\title{
Understanding Life Cycle Thinking and its Practical Application to Agri-Food System
}

\author{
Novizar Nazir

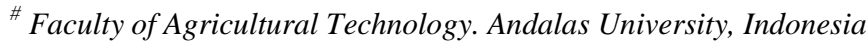 \\ E-mail:nazir_novizar@yahoo.com
}

\begin{abstract}
Global agri-food system will face great pressure to meet the continuing demands for food due to the increasing number of world population. The high demand requires an increase in food production and agricultural output, which, therefore, means more raw materials, water, energy, and other resources needed. Increasing the amount of these resources for agri-food system will harm the environment since carbon dioxide generated by the burning of fuel will then result in global warming and climate change. This paper discusses global issues related to sustainable agri-food system, such as climate change, sustainability, green products, food loss and food mileage relationships with emissions. It describes Life Cycle Thinking (LCT) philosophy and how LCT is operated into practical applications, using Spanish Agri-food system as an example, and challenges for Life Cycle Assessment (LCA) applications in supporting sustainable agri-food systems. Environmental impacts associated with agri-food system need to be reduced. The use of an LCA framework to determine the areas with the greatest impact and reduction strategies for agri-food operation is a viable strategy to reduce the environmental impacts in facing the increasing global demand. Nevertheless, the application of LCA in agri-food systems varies due to global, regional, and local differences in its practice. Thus, it makes it difficult for general LCAs to be conducted on agri-food system. Despite the increasing number of LCA studies in agri-food system, the literature on methodological aspects, and case studies, some challenges still need to be addressed to ensure that LCA provides significant results.
\end{abstract}

Keywords-sustainable agriculture; agri-food system; sustainability; climate change; life cycle thinking; life cycle assessment; environmental impact.

\section{INTRODUCTION}

Agri-food system faces many challenges. Despite its unquestionable contribution to human health and prosperity, agricultural production, food processing, food distribution and food consumption cause enormous environmental impacts. As the number of human population and wealthy people grow, food demand is increasing, putting more pressure on land. Other food production inputs such as for the use of pesticides, fertilizers, and other chemicals result in environmental changes, which, on the other hand, create challenges to agricultural production [1].

Agriculture also significantly contributes to the land degradation and anthropogenic global greenhouse gas emissions. It is responsible for $25 \%$ of carbon (mainly from deforestation), $50 \%$ of methane, and more than $75 \%$ of $\mathrm{N} 2 \mathrm{O}$, that are annually emitted by human activities [2].

An estimation of one-third of the world's cropland is losing topsoil, which is faster than the formation of new land. About $80 \%$ of new tropical farmlands are replacing forests as agricultural expansion in the tropical regions is mainly done by deforestation [4]. Agriculture conversion jeopardizes species-rich areas [5], which have hundreds of medicinal plants. Land use change significantly contributes to the increase of $\mathrm{CO} 2$ emission [6], and unprecedented water shortages in many parts of the world [7]. Widespread agricultural production losses increase due to a frequency of heat waves and precipitation extremes in the last decade [8].

While global food systems are increasingly in jeopardy by land degradation, climate change, and other stressors [9], a change towards sustainable food systems is crucial [1]. A sustainable development path will require essential and ultimately transformative changes of the global agriculture and food system to increase the availability and utilization of food, improve the quality of the environment and human health, and create more prosperous rural communities [9].

Awareness of the need for sustainable approaches to project design and implementation is increasing within the international community. The concept of sustainability in development was first described as a process to meet the needs of the present generation regardless the ability of the future generation to meet their needs [10]. Later, the concept has become a unifying theory in development works worldwide. The United Nations considers it as the primary approach to meeting development goals and calls for public participation in sustainability at all levels [11]. 
As food production systems and consumption patterns are among the leading factors giving impact on the environment, assessing and improving food related supply chains as much as possible is very necessary. Life cycle thinking (LCT) is a holistic approach and a fundamental concept for ensuring the transition towards more sustainable production and consumption patterns $[12,13]$.

A significant tool for LCT in guiding agri-food sustainability is life cycle assessment (LCA). LCA has been used widely to assess agricultural systems and food processing and manufacturing activities and compare alternatives "from the field to table" and to food waste management [13].

The objective of this research was to answer the following questions: (1) What are the global issues related to the need for the application of sustainable agri-food system; (2) what is Life Cycle Thinking by studying LCT practical application in evaluating sustainable Agri-Food system in Spain as an example, (3) what is the challenges faced in applying LCT in agri-food system.

\section{MATERIAL AND METHOD}

To answer the questions in this study, several stages of data collection are performed:

\section{A. Paper Selection}

52 references are used to find answers to three fundamental questions in this study. These references are mainly the result of a selection of international peerreviewed publications in English derived from major academic article databases, namely Elsevier (www.sciencedirect.com), Scopus (www.scopus.com) and Springer (www.springerlink.com), were examined using keyword search. The keywords used were: 'agri-food system and LCA"; "agriculture and climate change" and LCA review".

\section{B. Content Analysis}

Content analysis is carried out on selected references to view qualitative and quantitative aspects to get the major finding from each references.

\section{Hotspot Analysis}

The study on sustainable agri-food system in Spain is taken as an example of how to apply the Philosophy of LCT in viewing the sustainability of agri-food system in a country. The issue of agri-food system is a very complicated issue. If we want to make environmental improvements from agrifood system on a broad scale with diverse products, then LCT approach can be achieved by using hotspots analysis. Hotspot analysis identify of the most contributing value chain with the most impact categories.

Hotspots analysis is a methodological framework that allows for the rapid assimilation and analysis of a range of information sources, including life cycle based studies, market, and scientific research, expert opinion and stakeholder concerns. The outputs from this analysis can then be used to identify potential solutions and prioritize actions around the most significant economic, environmental, ethical and social sustainability impacts or benefits associated with a specific country, industry sector, organization, product portfolio, product category or individual product or service. Hotspot analysis is often used as a precursor to developing more detailed and granular information about sustainability [14].

\section{RESULT AND DISCUSSION}

\section{A. Global Issue Related to Agri-Food System}

\section{1) Climate Change and Agriculture.}

Climate change occurs due to increased concentrations of greenhouse gases (GHG) such as carbon dioxide (CO2), nitrous oxide (N2O), and methane (CH4). Increasing GHG emissions are related to economic activity, particularly related to energy, industry, transportation and land use patterns including agricultural production and deforestation. Agriculture, including land use change and forestry (LUCF), contributes to nearly one-fourth of global GHG emissions [Fig.1] [15].

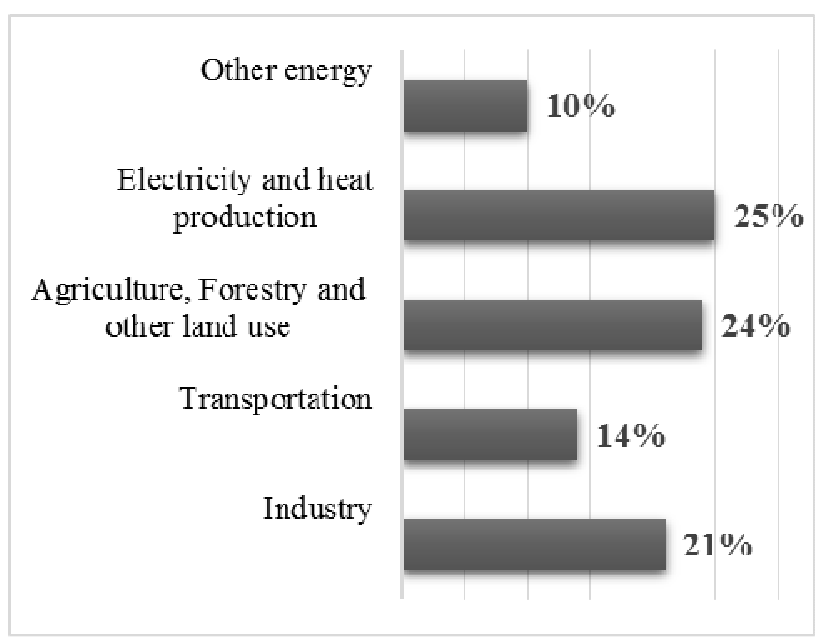

Fig.1. Global greenhouse gas emissions which are broken down by the economic activities. Source: IPCC [15]

At the same time, the farm also generates substantial $\mathrm{CO}_{2}$ fluxes, both through photosynthesis and respiration. The release of carbon, however, is produced by the conversion of forested land. Then, specific GHG emissions arising from agricultural activity accounts for other sectors, such as those relating to (upstream) manufacture of equipment, fertilizers, pesticides, on-farm use of fuels and the transportation of agricultural products.

Climate change also has a considerable negative impact on agricultural production, causing output reductions which will significantly affect parts of the developing world. As a result of a decrease in production, food security will be affected by climate change. Thus, climate change alone is predicted to increase the number of food insecure by an additional 5 to 170 million people by 2080, especially in Africa [16].

\section{2) How Green is Your Product}

Pressure on businesses to "go green" is overgrowing, but it is not coming from the government. Perhaps surprisingly, the driving force behind more sustainable product design is, in fact, market pressure! A 2015 global survey conducted by Nielsen found that $66 \%$ of respondents are willing to pay 
more for sustainable goods, up from $55 \%$ in 2014 . The study consisted of 30,000 consumers in 60 countries across the world. And it's not just the wealthy that are willing to pay more-results were consistent across regions and income levels. This survey demonstrates the growing desire of consumers for more sustainable products [17].

As we move into the future, decisions on food purchases will increasingly be influenced not only by price and quality but also by social and environmental factors such as the sustainability of technologies used for food production and processing and their ecological and health impacts. Growing consumer awareness about the effects of processing and production practices on the environment, the high energy consumption of specific processes, health impacts of some of the technologies used in processing, and a heightened social and industrial consciousness to reduce the carbonfootprint are examples of factors influencing food choice [18].

One of the indicators of a green product is ecolabel. In determining ecolabels criteria, the following are considered the most significant environmental impacts: the impact on climate change, the effect on nature and biodiversity, energy and resource consumption, generation of waste, emissions to all environmental media, pollution through physical effects and use and release of hazardous substances [19]. It is therefore evident that ecological impacts shall be identified by examination of the interactions of products/services with the environment, including the use of energy and natural resources, from a life-cycle perspective. Within the Ecolabel Regulation, Life Cycle Assessment considerations play a crucial role to highlight 'hot spots' in the entire production chain of the considered products/services and help to identify the most appropriate set of ecological criteria available for answering to those as mentioned earlier, preliminary conditions [20].

\section{3) Sustainability}

Over the long-term sustainability must: (a) meet the needs of food and human fiber; (b) improving the quality of the environment; (c) utilize non-renewable agricultural resources and resources efficiently and integrate appropriate natural biological cycles and controls; (d) maintain the economic feasibility of farming operations; and (e) improving the life quality of farmers and society as a whole [20]. The goal of sustainable agriculture is to maximize the net benefits that society receives from agricultural production of food and fiber and ecosystem services. This purpose will require increased crop yields, increased efficiency of nitrogen, phosphorus and water use, ecologically based management practices, judicious use of pesticides and antibiotics, and significant changes in some livestock production practices [21].

A doubling of in global food demand projected for the next 50 years poses enormous challenges for the sustainability both of food production and of terrestrial and aquatic ecosystems and the services they provide to society [22].

Ensuring a transition to a more sustainable production and consumption pattern, a holistic approach and life-cycle thinking is required. LCT is increasingly seen as an essential concept to support this goal. The LCT of the food- related supply chain continues to grow since food production systems and consumption patterns are among the key drivers of environmental impact [13].

\section{4) Losses in the Agri-food supply chain}

Food Loss refers to food that during its process in the food supply chain gets spilled, spoilt or otherwise lost, or incurs a reduction of quality and value before it reaches its final product stage. Food loss typically takes place at production, postharvest, processing and distribution stages in the food supply chain [23]. "Food losses can be qualitative, such as reduced nutrient value and undesirable changes to taste, texture, or color, or quantitative as measured by decreased weight or volume" [24].

The problem of food losses is critical in the fight against hunger, increasing income and improving food security in the world's poorest countries. Food losses affect food security for the poor, on food quality and safety, on economic and environmental development [25].

In general, food losses will be affected by the choice and pattern of crop production, internal infrastructure and capacity, marketing chains and distribution channels, and consumer buying practices and food use. Regardless of the level of economic development and maturity of the system in a country, food losses must be kept to a minimum. Food loss is a waste of resources used in production such as land, water, energy, and input. Producing food that will not be consumed causes unnecessary $\mathrm{CO} 2$ emissions in addition to the loss of economic value of the food produced [25].

\section{5) Food Miles and emissions}

A simple definition of this 'Food Miles' concept would be: 'the number of miles (kilometers) product has to be transported from the farmer/grower to various stages of production until it reaches the supermarket and finally the plate of the consumer.' It has been born out of concern for the environment, especially regarding greenhouse gas emissions such as carbon dioxide and the global warming arising from this. The argument is that the longer the transport distance (food miles), the more energy is consumed, the more fossil fuels are burned, and consequently the more greenhouse gases are released into the air, which causes global warming (Fig.2). Air freight is viewed as the most environmentally damaging form of food transportation. It produces between 40 and 200 times the $\mathrm{CO} 2$ emissions of marine transport [26].

\section{B. What Is Life Cycle Thinking?}

Every product has 'life.' During its lifetime the product has a cycle. That is what is called the life cycle. Products (goods and services) contribute to various environmental impacts over their lifetime. The concept that accounts for the upstream and downstream benefits and trade-offs is called Life Cycle Thinking (LCT). LCT seeks to identify environmental improvement opportunities at all stages of its life cycle, from the extraction of raw material and conversion, through manufacturing of the product, distribution, use, and fate at the end-of-life stage. Its primary objective is to provide a structured and comprehensive approach in support of the overall reduction of product impacts and to help optimize benefits [27, 28]. 


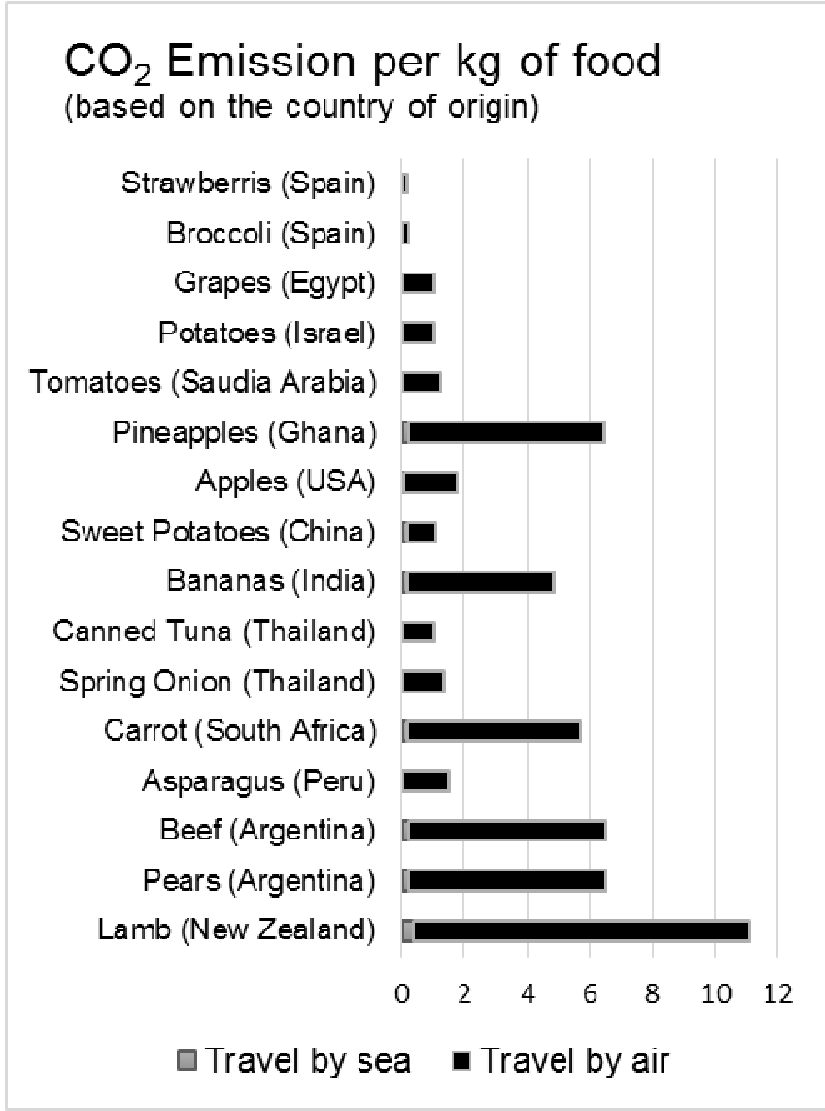

Fig.2. $\mathrm{CO}_{2}$ emission per $\mathrm{kg}$ of food which is traveled to the UK from various countries (Emissions are calculated by multiplying the distance to potential emissions according to Wakeland et al. [28,29]

\section{1) The Philosophy of LCT}

Life cycle thinking plays a vital role in the concept of pollution prevention in including the whole product life cycle and sustainability. Source reduction in a product life cycle perspective is then equivalent to eco-design principles and the "6 RE philosophy"[30].

Re-1 Re-think the product and its functions. For example,the product may be used more efficiently, there by reducing energy use and other natural resources

Re-2 Re-duce energy and material consumption throughout a product's life cycle.

Re-3 Re-place harmful substances with more environmentally friendly alternatives.

Re-4 Re-cycle. Select materials that can be recycled, and build the product so that it is disassembled easier for recycling.

Re-5 Re-use. Design the product so parts can be reused.

Re-6 Re-pair. Make the product easy to repair so that the product does not yet need to be replaced. In each life cycle stage there is the potential to lower resource consumption and improve the performance of products

\section{2) Key Principles Of Life-Cycle Thinking}

The product life cycle (Fig. 3) is shown in five distinct phases: Raw material extraction, material processing, product manufacture, product consumption/use and final disposition/waste management. All of which interact with the environment. Each stage uses energy, water, and resources and has waste, emission, and a particular environmental impact. In each lifecycle step, there is the potential to reduce energy, water, and resource consumption and improve the performance of products. In this context, LCT is essential to sustainable use and production [31, 32] as well as, to sustainable development.

The primary goals of life cycle thinking are to reduce a product's resource use and emissions to the environment as well as improve its socio-economic performance throughout its life cycle [30]. This goal may facilitate links between the economic, social and environmental dimensions within an organization and throughout its entire value chain [28].

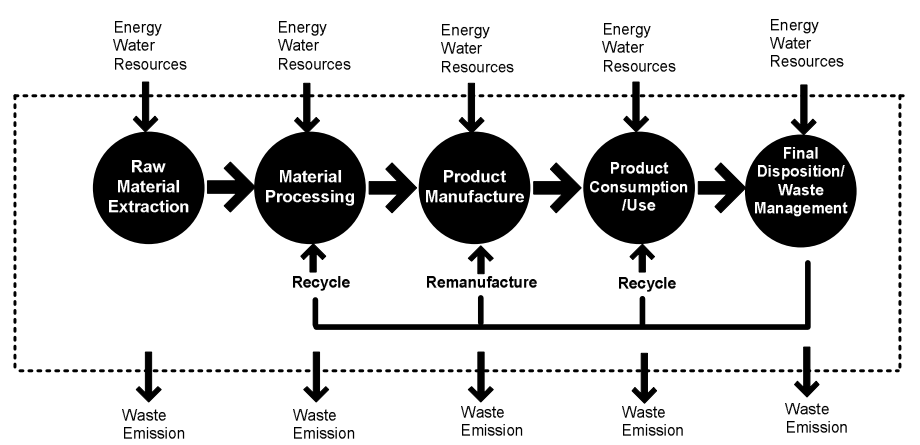

Fig. 3. Life cycle phases of a product.

\section{3) How to operate LCT into practical application}

The primary operational tool of "Life Cycle Thinking" is Life Cycle Assessment. The objectives of the LCA are to form a complete picture of the interactions with the environment of the products, helping to understand the environmental consequences caused directly or indirectly, and then provide the information needed to define the environmentally sustainable behaviors and identify opportunities for improvement in order to achieve the best solutions to intervene on the environmental conditions [33].

The methodology for conducting LCA for individual products and services has been internationally recognized and documented by the ISO 14040 [33]. According to ISO, LCA consists of the four distinctive stages (Fig. 4):

The LCA studies include four phases:

1. Goal and Scope Definition (ISO 14041)

2. Life Cycle Inventory Analysis - LCI (ISO 14041)

3. Life Cycle Impact Assessment - LCIA (ISO 14042)

4. Life Cycle Interpretation and Improvement. (LCII) (ISO 14043)

Goal and Scope definition. The definition of goal and scope, sets out the specific LCA basic methodology that must be performed to ensure uniformity of analysis. This part of the study is very important because it is the stage of how this section governs the entire agricultural system will be disrupted.Spending time to determine how the LCA analysis will occur adequately helps decrease the time needed to address difficulties when faced with one of the many challenges associated with the evaluation of agricultural activities [35]. 


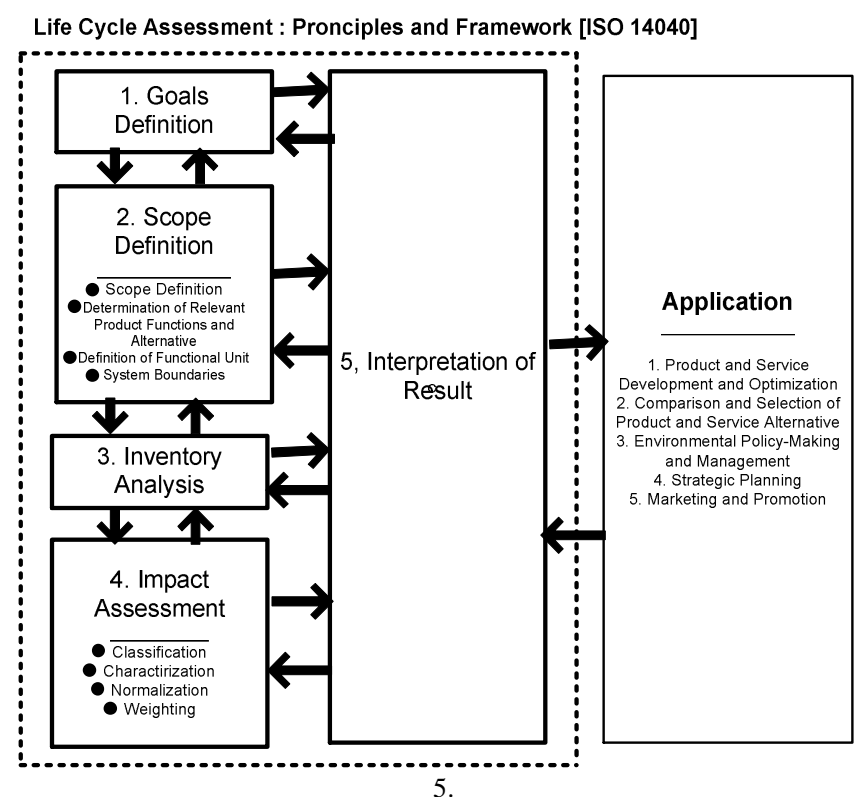

Fig. 4. An overview of the critical stages and possible applications of LCA. Source Adopted Modified from ISO 14040 [33].

The goal definition is the first phase of an LCA and determines the purpose of a study in detail. The goal definition based on the ISO standard requirements contains six aspects: 1. Implementation of results 2. Limitations due to methodological choices 3 . The decision context and reasons for conducting an assessment; 4. Goal 5. Comparative study to be disclosed to the public 6. Surveyors and other influential actors. Each aspect must be considered when performing an LCA. Issues 1 and 3 are central for doing an LCA because they have the pervasive influence on decisions made in later LCA phases. On the other hand, aspects 2, 4, 5 and 6 mainly relate to communicating the results of an LCA [36].

The scope definition is the next phase of an LCA. It sets what product systems are to be assessed and how this assessment should take place. A scope definition consists of the following nine scope items: 1 . Deliverables 2 . The object of the evaluation 3. LCI modeling framework and handling of multifunctional processes 4. System boundaries and completeness requirements 5. Representativeness of LCI data 6. Preparation of the basis for the impact assessment 7. Special requirements for system comparisons 8 . Needs for critical review 9. Planning reporting of results. Each item must be considered when performing an LCA. Items 2-6 are central for doing an LCA because these have a pervasive influence on decisions made in later LCA phases. Aspects 1, 7, 8 and 9 mainly relate to reporting and communicating an LCA study [37].

A system boundary determines what will and will not be addressed in the LCA. Some parts of the scope need to be addressed while setting this boundary but most importantly it needs to be the primary goal(s) of the study. Establishing system boundaries may not be too complicated in cases related to industrial products with direct current-dominated emissions with fairly uniform results throughout the year. Environmental impacts associated with agriculture are dominated by temporarily varying, nonpoint sources, both seasonally and yearly [35]. System boundaries demarcate the boundaries between the studied product system and (1) the surrounding economy (technosphere) and (2) the environment (ecosphere). "Completeness requirements" is a related concept that can be used to determine what processes should be included within the system boundaries to reach the degree of completeness in the product system modeling that is needed to agree with the goal of a study (see details below). The setting of the system boundaries can have a tremendous influence on LCA results because they determine the unit processes from which environmental impacts should be quantified. At this point in the scope definition, the system boundaries should be represented in a diagram that provides an overview of which parts of the studied product system(s) that are included and which are excluded [37].

It is essential to define the functional unit right because it significantly influences the way LCA is performed, its results and interpretation, especially in comparative studies. This is because the functional unit serves as a reference point for deciding which unit processes to include and to what extent they are drawn upon. It is therefore essential to ensure that the functional unit fully captures the relevant functional aspects of the studied systems [37].

Functional units are quantitative values associated with system functions. (eg., function: corn production, functional unit: $\mathrm{kg} / \mathrm{ha}$ ). It depends on the system being assessed, and the goals of the LCA defining functional units can become complicated for agricultural operations. From the perspective of farming as a whole, it is easy to identify several products whose production can vary each year depending on the crop rotation schedule and the variety of results. To address these challenges, then the allocation procedure is required. The allocation procedure is an operation to share the impact of various products derived from agricultural activities. This method is an area where a possible bias indicating a product with a decrease has implications while another inflating can be introduced [35].

Life Cycle Inventory Analysis. The inventory analysis is the third and often most time-consuming part of an LCA. The investigation is guided by the goal and scope definition, and its core activity is the collection and compilation of data on elementary flows from all processes in the studied product system(s) drawing on a combination of different sources. The output is a compiled inventory of primary streams that is used as the basis of the subsequent life cycle impact assessment phase [38].

Completion of the life cycle inventory analysis collects and calculates emissions data. These values considering the system boundary and allocation procedure as described in the scope. The data can be divided into several categories such as energy, raw materials, products, waste, air emissions, water emissions, and discharges to the soil. After collecting the data, the inventory values are calculated with allocation procedure and functional unit in mind [35].

Life Cycle Impact Assessment (LCIA). The LCIA phase is the study of the environmental impact caused by a manufacturing process or from a business, made through the use of some aggregate indicators of international use that help quantify impacts and compare alternative processes or products. The impact analysis is divided into four phases: classification, characterization, standardization, and 
evaluation. These last two steps are not mandatory for the application of the system [33].

The Life Cycle Impact Assessment (LCIA) where the life cycle inventory's information on elementary flows is translated into environmental impact scores. In contrast to the three other LCA phases, LCIA is in practice automated mainly by LCA software, but the underlying principles, models, and factors should still be well understood by practitioners to ensure the insight that is needed for a qualified interpretation of the results [39].

Life Cycle Impact Interpretation [LCII]. The interpretation is the final phase of an LCA where the results of the other steps are considered together and analyzed in the light of the uncertainties of the applied data and the assumptions that have been made and documented throughout the study [40].

The phase LCII concerns the interpretation of the results, the identification of critical environmental issues and, at the same time, highlighting the potential for technical and managerial improvement of the life cycle of the product being studied. We proceeded to apply the methodology of LCA to a company of the olive sector, to assess the environmental impact [33].

\section{The Application of life cycle thinking perspective on Spain's agri-food system}

\section{1) Life Cycle Thinking Perspective of Agri-food System}

Traditionally, energy balances in agricultural production have been used to calculate the impact of food on the Spanish economy in physical terms. However, this tool is insufficient. Human diet has undergone substantial changes in recent decades. Between production and consumption, previously nonexistent or insignificant processes such as transportation, packaging, processing, distribution, preservation, etc. have come to the fore [41]. Amate and Molina [41] analyzed the energy cost of the Spanish agrifood (AFS) system in the year 2000 to ascertain the relative importance of each link in the agri-food chain. This information is substantial when it comes to designing any strategy for sustainable de-growth.

The analysis aims to place the current environmental problems of agriculture and food at the center of the debate surrounding 'sustainable de-growth'. To do this, a change in approach is essential, evaluating the physical cost of feeding the Spanish population as a whole, beyond the agricultural sector. For this purpose, the total energy use of the Spanish agri-food sector (AFS) was calculated, from agricultural production to domestic consumption. Breaking this total figure down into specific processes, we can identify which parts of the chain give rise to the majority of the energy consumed and, consequently, propose alternatives for sustainable de-growth [41].

All AFS are inserted into international markets where they exchange materials and energy with many other sectors and territories. It is impossible to reconstruct the precise boundaries of their biophysical structure with the statistical data and case studies currently available. Spanish agriculture, for example, consumes energy to produce not only food but also other types of goods such as fibers, fuels, etc., which cannot be distinguished. Furthermore, the energy consumption of the AFS transcends national borders in complex networks that make it impossible to evaluate the energy consumed in other territories destined for the Spanish market. Similarly, there is consumption in activities of other sectors, such as the services sector (for example, in advertising) which has been impossible to estimate [41].

Amate and Molina [41] took into consideration the energy consumption of six main activities included in the Spanish national agri-food chain: agricultural production, processing, packaging, distribution, transport and domestic energy consumption. The energy used to produce imported food products which are consumed in Spain is not taken into consideration, although some of these products are eventually consumed in Spain. In the case of transport, in addition to the transportation carried out within Spain (transport between farms, processing centres, shops or homes), we took into account the energy consumption involved in the exportation and importation of agrarian and food products on the understanding that these flows are essential in order to maintain the functioning of the AFS (see Fig. 5). On the other hand, the energy consumed to produce food that will possibly be later exported is taken into account.

For these calculations, the consumption of direct energy by each of these activities is considered including, where possible, the total energy consumed in the production of each product involved using life cycle analysis (for the production of fertilizers, treatments or packaging) [41].

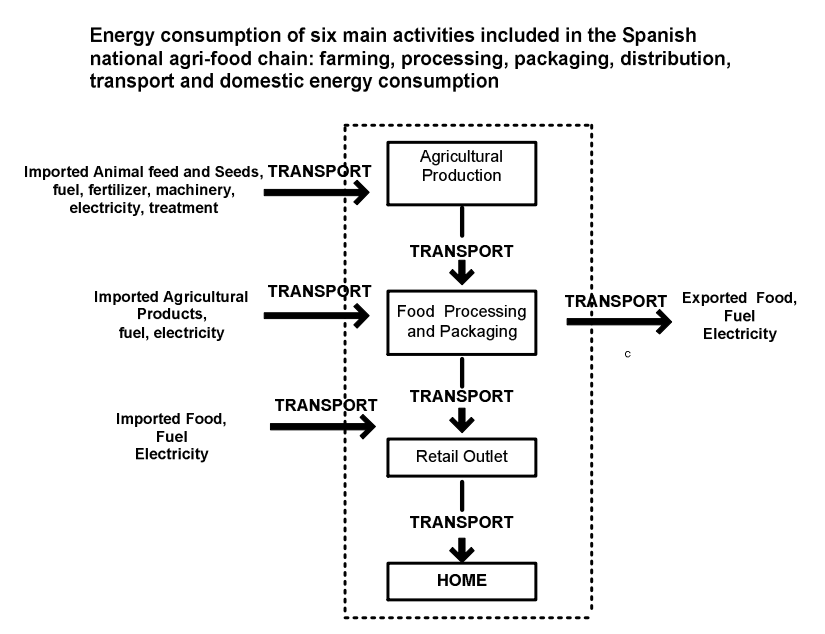

Fig. 5. System boundaries. Activities considered and type of consumption taken into account for each activity [Modified from Amate and Molina [41].

\section{2) Energy Consumption}

In short, the results reveal an activity that requires the use of a very significant amount of energy, mostly from fossil fuels. In each and every one of the processes involved in the food chain, the consumption of resources multiples, resources that not only make the end products more expensive, but are also responsible for so many other environmental problems, such as the depletion of scarce resources, climate change or acidification In view of the data presented, any strategy for sustainable degrowth in Spain must pay particular attention to farming production, to its transportation, the packaging of foodstuffs and their preservation/storage and preparation in the home. Together, they represent over three-quarters of the total amount of primary energy consumed in the agri-food system [41]. 
The energy consumption that takes place in the agricultural sector represents just over a third of the total for the Spanish AFS, with the remaining two-thirds originating in the transportation of foodstuffs, their industrial processing, packaging, sale, preservation, and consumption (Table 1).

TABLE I

ENERGY CONSUMPTION IN SPAIN AGRI-FOOD CHAIN [ADOPTED FROM AMATE AND Molina [41]

\begin{tabular}{|l|l|l|}
\hline \multirow{2}{*}{ Spain Agri-Food Chain } & Energy Consumption (PJ) \\
\cline { 2 - 3 } & Energy (PJ) & Proportion (\%) \\
\hline Household consumption & 258 & $18.35 \%$ \\
\hline Food retail & 135 & $9.61 \%$ \\
\hline Packaging & 150 & $10.64 \%$ \\
\hline Processing & 138 & $9.83 \%$ \\
\hline Transportation & 245 & $17.43 \%$ \\
\hline Agricultural Production & 481 & $34.14 \%$ \\
\hline $\begin{array}{l}\text { Total Energy consumed } \\
\text { (PJ) }\end{array}$ & 1408 & $100 \%$ \\
\hline $\begin{array}{l}\text { Energy contained in the } \\
\text { food consumed (PJ) }\end{array}$ & 235 & $17 \%$ \\
\hline
\end{tabular}

In total $1408 \mathrm{PJ}$ to satisfy the food requirements of the Spanish population, whereas the energy contained in the food consumed barely reaches 235 PJ. In other words, for each unit of energy available in the form of food, 6 units of energy have been consumed in its production, distribution, transportation, and preparation (Fig. 6). For every unit of energy consumed in the form of food (excluding losses due to waste and spoiling), an investment of 7.4 is required [41].

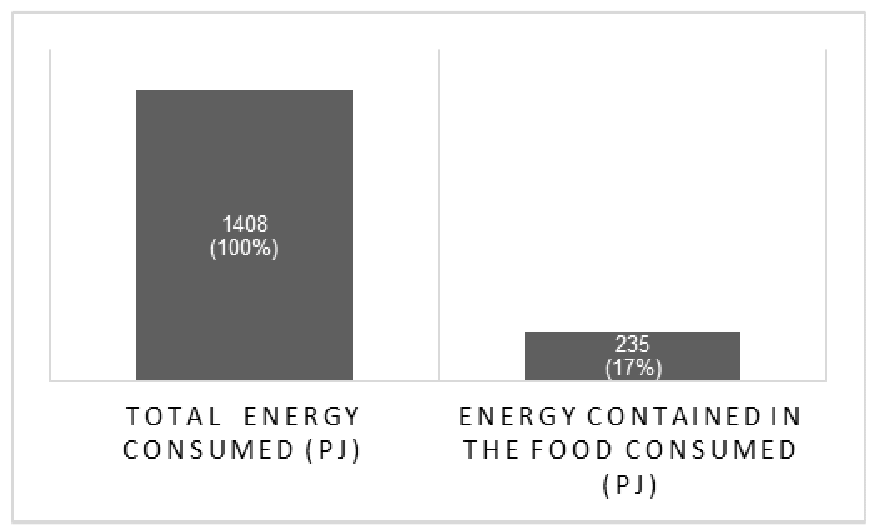

Fig. 6. The first column shows the total energy consumption of the Spanish agri-food sector in the year 2000 by type of activity and the different percentages. The second shows the amount of food available in Spain measured in energy (nutritional values) [Modified from Amate and Molina [41].

\section{3) Implication}

By evaluating the energy costs of the Spanish agri-food system, any strategy for sustainable de-growth in Spain must pay particular attention to farming production, to its transportation, the packaging of foodstuffs and their preservation/storage and preparation in the home. Together, they represent more than three-quarters of the total amount of primary energy consumed in the agri-food system [41].

Agricultural production is responsible for more than onethird of this invested in the entire food system. The processes involved in the transportation, processing, packaging, sale in retail food outlets, and the preservation/storage and preparation of food in homes are responsible for the remaining two-thirds of the energy invested in the entire food process. Economic de-growth, to be sustainable, must pay particular attention to how this process is carried out. Only a shift towards organic farming and corresponding changes in consumption patterns can contribute to substantial reductions in resource use in the food system and sustainable de-growth. The way in which it can be achieved, even improving the quality of what we eat and without reducing agrarian income and employment, is to switch to organic farming and to change over to a more vegetarian diet, with the emphasis on seasonal products produced locally [41].

The results of this research based on LCT perspective show that feeding the Spanish population is an inefficient process: the Spanish AFS currently consumes 1408 PJ, while all of its residents combined consume only 190 PJ. Agricultural production consumes $34 \%$ of primary energy. It is effectively a significant source of inefficiency. But it is not the only one. Processes such as food preparation and preservation at home consume $18 \%$ of primary energy. Transportation and packaging consume $17 \%$ and $10 \%$ of primary energy respectively. This data illustrates that the way we feed ourselves is not sustainable. The results of this study, written by Amate and Molina [41] make a strong point that the fundamental transformation of AFS is required. Movements towards organic farming and appropriate new consumption patterns (i.e., local seasonal food, less meat consumption) can reduce resource use in AFS and contribute to sustainable de-growth in Spain.

\section{The challenges for life cycle assessment in supporting sustainable agri-food systems}

There are some critical dimensions of agri-food supply chains that make them different from those in other production sectors [42]. This aspect including (1) seasonality of demand and supply, (2) consumer issues of traceability and risk management related to health, nutrition, and safety, and (3) the impact of food production on the environment through extensive resource use, including water and land, and from the significant greenhouse gas emissions and waste resulting from agricultural production [42].

LCA has been applied extensively to the evaluation of agricultural systems, processing and manufacturing activities, and for comparing alternatives "from the field to table" and up to food waste management. However, despite the increasing number of LCA agri-food studies and a flourishing literature on both methodological aspects and case studies, several challenges still need to be addressed to ensure that LCA is delivering robust results [35].

Methodological aspects. The main challenges highlighted by Notarnicola [13] in their analysis are related to different methodological aspects. The inherent variability of the agricultural system is one element affecting the assessment at the inventory, impact assessment, and interpretation phases. Firstly, there is a need to move beyond the simple rationale that more output per hectare is sufficient to ensure increasing eco-efficiency. In fact, in spite of increased efficiency in land use appears to be a reasonable way, along with increased pressure on 
agricultural land for other purposes such as bioenergy, and the pressure of urbanization and desertification, the current LCA method is incomplete and can not conduct a comprehensive assessment of some an essential aspect of long-term sustainable food production [13].

System boundaries are defined based on the goals of the single study. As a minimum, the analysis of food consumption should cover the production chain up to the point of sale including agricultural production, processing, transport, and distribution. Studies often focus on the farming phase and ignore further stages, because they only address the improvement in this step. However, if the downstream stages contribute significantly to the overall impact and differ between the products compared, such studies cannot address the full implications of food production. Additional steps after the point of sale might be considered depending on the goal and scope of the analysis, e.g., home transportation, chilling, cooking, treatment of wastes, and effluents. Some studies are related to methodological issues of LCA for agri-food systems, representing particular challenges. In agriculture, many emissions cannot be measured directly as the final emission like end-pipe-line, but it must be estimated through a model approaching its nature. Emissions depend heavily on climate, soil, and topography and can vary greatly, even in the same region. Several studies have highlighted the differences in production in the different areas, using various agricultural practices or variability between each farm [43].

Modelling Approach. Current LCA modeling approaches should be complemented by other approaches to improve the understanding of what is happening in-field (and potentially subject to specific comparisons, e.g., organic versus nonorganic agriculture), and what is off-field and which is affected by the reliability of secondary datasets. For example, for ecotoxicity-related impacts, frequently the relative share of impacts associated with the substances applied on the field (e.g., pesticides) is limited compared to the elements used in background systems that are off-field [13].

Modeling issues specific to agri-food systems. The distinction between technosphere and ecosphere about modeling of environmental impact, Multi-functional biological systems. Co-production is a standard issue in food LCA with economic or physical allocation being the most common approach in food product studies due to ease of data collection. System expansion should be preferred to be in line with ISO; however, the method of system expansion is more complicated and more demanding on data collection. Emission modeling on inventory analysis (fertilizers, pesticides, and machinery) is further complicated by several other factors typical of agricultural systems. In particular, it is known that emission flows are closely related to the input of pesticides and fertilizers themselves, not site-specific soil and climate conditions only. Several guidelines for inventory modeling are provided in different studies and reports, amongst which Nemehek [44] is a valuable reference.

Modeling the end of life management of products is still problematic. Data on recycling processes are still sparse; models to characterize the emissions from landfill sites must be improved; data on food losses at home have a poor representativeness. Some impact pathways are difficult to model, and although approaches are proposed in the scientific literature, consensus does not always exist. Consequently, there are missing characterization factors for a particular inventory, or the underlying essential uncertainties, especially for primary flows associated with indicators of damage to ecosystem quality [45].

Function and Functional Unit. One of the essential characteristics in the applications of LCA to agriculture is the use of plural functional units. Agricultural land, an area, a livestock unit and a product such as milk are the examples of plural functional units [46]. Recent discussions on multifunctionality of agriculture give an interpretation on the plurality of functional units. There is a definite need for consensus on more meaningful FUs for food products [13]. Both Hayashi [47] and Boer [48] propose that when assessing organic farming practices use of a functional unit (unit of measure, e.g., $\mathrm{kg}$ of product) and the product allocation procedure affect the outcomes of the analysis.

Data requirements, A human food consisting many food products and each food product may be composed of many different ingredients. Each ingredient may have a varying degree of processing, and the raw materials used may originate from different countries. Therefore, one faces a high data demand and level of complexity, when trying to assess the environmental impacts of the diet of a whole population [43]. As is often the case in food-related LCA, the datasets in these databases in Food LCA are usually created using data representing specific sites at specific times. This means that different databases cannot be used interchangeably and need to be used with caution by LCA practitioners. In many cases, the data are presented in a nontransparent manner that will not allow LCA practitioners to adapt such data to their specific case studies accurately. This can undoubtedly lead to studies that have ambiguous interpretations and conclusions that are not comparable to those of other studies [13]. Available inventory databases do not cover entirely or accurately all sectors of human activities. This is especially the case for agriculture and food processing activities databases [45].

Consumers' choices and behavior. The structure of food systems is very much influenced by consumers' choices and behaviors. Understanding this will lead to better modeling (e.g., the use phase). It will also lead to consideration of key aspects affecting the choice of products, the potential for dietary changes to less impactful diets, perceived differences in the quality of the environment associated with products, how products are consumed and, even to the extent of waste related to the system of food [13].

The environmental impact of food is also influenced by consumer behavior. The consumer choice of diet has a substantial effect on the outcome as shown for example by Tilman and Clark [49]. Food wasted at home can considerably increase the impacts on the environment [50]. Food preparation methods can create considerable variation in environmental impacts [51] especially when considering the decrease in the size of households, and therefore, the group of prepared foods is also smaller. As the amount of cooked food is reduced, the energy used is less per kilogram compared to cooking more significant amounts [52]. Food storage can also have a substantial effect on energy consumption and improvement. Due to the higher human 
mobility and changing eating habits, more and more food is eaten outdoors. This condition will create a new level of complexity. Thus data, e.g., on preparation and serving in restaurants are necessary in order to assess the full environmental impacts of food consumption Modelling food waste in LCA is common practice because the reference flow is defined as a part of the functional unit, and thus the inventory will include waste generated along the chain (relative to the reference flow) [13].

Amate and Molina [41] conducted an LCT approach on the agri-food system in Spain with a focus on the energy consumption of all value chains. Reduce energy consumption is a philosophy of LCT approach [30]. Fig. 6 show the agri-food value chain and potential hotspots that can lead to changes in energy consumption and environmental changes which consist of the choice of input, technology, behavior, and mode of transportation. LCT approach can be made by calculating the consumption energy at all hotspots. Based on this hotspot analysis it can be found the potential solution and priority actions for environmental improvement.

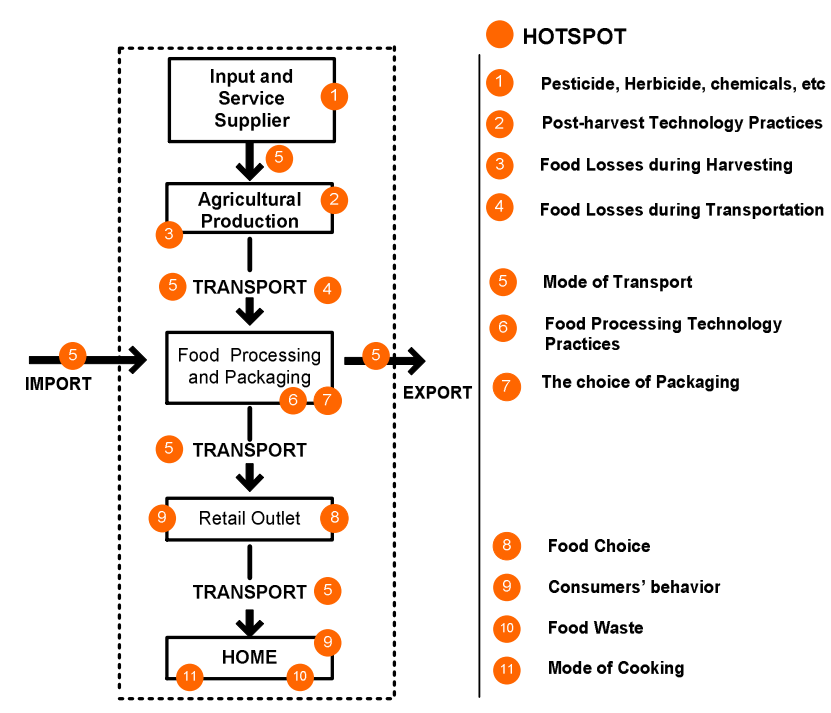

Fig.6. Agri-Food Value Chain and Potential Hotspots

\section{CONCLUSIONS}

Sustainability plays a crucial role in transforming both the environment and the society to adapt to the rigorous demands of the future. In this context, LCT can promote a more sustainable production and consumption levels and help communities to use their financially and financially limited resources more efficiently.

The agri-food sector is incredibly diverse producing a large number of products and services vital to humanity. Variations exist globally, regionally, and locally in management practices that make it difficult for a general LCA to be conducted on agricultural products. The use of an LCT within LCA framework to determine areas of most significant impact and compare reduction strategies of farming operations is a feasible strategy for reducing environmental impacts in the face of increased global demand.
LCT approach can be made by using the hotspots analysis by calculating the consumption of energy at all hotspots in all agri-food system values chain.

Despite the increasing number of LCA agri-food studies and a flourishing literature on both methodological aspects and case studies, several challenges still need to be addressed to ensure that LCA is delivering significant results.

\section{REFERENCES}

[1] Foresight. The Future of Food and Farming. Final Project Report The Government Office for Science. United Kingdom, London. 2011

[2] F.N Tubiello, J.F. Soussana, S.M. Howden, "Crop and pasture response to climate change", Proc. Natl. Acad. Sci. USA 104, 19686- 19690

[3] E. Nkonya, N. Gerber, P. Baumgartner, The Economics of Land Degradation toward an Integrated Global Assessment. In: Development Economics and Policy, vol. 66. Springer, Frankfurt am Main, Berlin, Bern, Bruxelles, New York, Oxford, 2011.

[4] J.A Foley, N. Ramankutty, K.A Brauman, et al., 2011." Solutions for a cultivated planet", Nature 478, 337-342., 2011.

[5] TEEB, The Economics of Ecosystems and Biodiversity for National and International Policy Makers . Summary: Responding to the Value of Nature. United Nations Environment Program, ISBN 978-39813410-0-3, p. 47, 2009.

[6] IPCC (Intergovernmental Panel on Climate Change),. "Climate change: impacts, adaptation and vulnerability". In: Parry,M.L., Canziani, O.F., Palutikof, J.P., van der Linden, P.J., Hanson, C.E. (Eds.), Contribution of Working Group II to the Fourth Assessment Report of the ntergovernmental Panel on Climate Change. Cambridge University Press, Cambridge, New York, 2007.

[7] E. Fereres, F. Orgaz, V. Gonzalez-Dugo, "Reflections on food security under water scarcity". J. Exp. Bot. 62, 4079-4086

[8] D. Coumou, S. Rahmstorf,. "A decade of weather extremes". Nat. Clim. Change 452, 1-5, 2011.

[9] SDSN (Sustainable Development Solutions Network). .2013 Solutions for Sustainable Agriculture and Food Systems Technical Report For The Post-2015 Development Agenda. http://unsdsn.org/wp-content/uploads/2014/02/130919-TG07Agriculture-Report-WEB.pdf

[10] WCED (World Commission on Environment and Development), (1987). Our Common Future. Oxford University Press.

[11] UNCED (United Nation Conference on Environment and Development), Agenda 21. https://sustainabledevelopment.un.org/ content/ documents/Agenda21.pdf.

[12] W, Klöpffer, "Life-Cycle Based Methods for Sustainable Product Development". The International Journal of Life Cycle Assessment 8 (3) 157-159. 2003.

[13] B. Notarnicola, S. Sala , A. Anton, S. J. McLaren , E.Saouter, U. Sonesson. "The role of life cycle assessment in supporting sustainable agri-food systems: A review of the challenges", Journal of Cleaner Production 140 (2017) 399-409.

[14] UNEP. Final report UNEP/SETAC Life Cycle Initiative - Flagship Project 3a (Phase 1), "Hotspots Analysis: mapping of existing methodologies, tools and guidance and initial recommendations for the development of global guidance, 179 p, 2014

[15] IPCC, 2014: Climate Change 2014: Mitigation of Climate Change. Contribution of Working Group III to the Fifth Assessment Report of the Intergovernmental Panel on Climate Change [Edenhofer, O., R. Pichs-Madruga, Y. Sokona, E. Farahani, S. Kadner, K. Seyboth, A. Adler, I. Baum, S. Brunner, P. Eickemeier, B. Kriemann, J. Savolainen, S. Schlömer, C. von Stechow, T. Zwickel and J.C. Minx (eds.)]. Cambridge University Press, Cambridge, United Kingdom and New York, NY, USA

[16] M. W. Rosegrant, M. Ewing, G. Yohe, I. Burton, S. Huq, R. V.Santos. Climate Change and wakelan Agriculture: Threats and Opportunities. Published by Deutsche Gesellschaft für Technische Zusammenarbeit (GTZ) GmbH Climate Protection Programme for Developing Countries Postfach 518065760 Eschborn / Germany. 32 p., 2008.

[17] AL Innauzi. Greener Products: The Making And Marketing Of Sustainable Brands. Second Edition. Crc Press. Taylor \& Francis Group.6000 Broken Sound Parkway NW, Suite 300. Boca Raton, FL 33487-2742, 2017. 
[18] J.I. Boye and Y. Arcand (eds.), Green Technologies in Food Production and Processing, Food Engineering Series, DOI 10.1007/978-1-4614-1587-9_1, (C) Springer Science+Business Media, LLC , 2012.

[19] H. Sengstschmid, N. Sprong, O. Schmid, N. Stockebrand, H. Stolz, A. Spiller. 2010. EU Ecolabel for food and feed products - feasibility. Study. George-August-Universitat. Gottingen. Sengthttp://ec.europa.eu/environment/ecolabel/documents/Ecolabel_f or_food_final_report.pdf

[20] G. L. Baldo, S. Rollino, G. S. M. Fieschi, "The use of LCA to develop eco-label criteria for hard floor coverings on behalf of the european flower" The International Journal of Life Cycle Assessment Volume 7, Issue 5, pp 269-275| , 2002.

[21] S. Velten, J. Leventon, N. Jager and J. Newig. "Review What Is Sustainable Agriculture? A Systematic Review", Institute for Sustainability Sustainability 2015, 7, 7833-7865; doi:10.3390/su7067833 sustainability ISSN 2071-1050.

[22] D. Tilman, Kenneth G. Cassman, Pamela A. Matson, Rosamond Naylor \& Stephen Polasky. 2002. Agricultural sustainability and intensive production practices. Nature 418, 671-677 (8 August 2002)

[23] M. Bagherzadeh, M. Inamura and H. Jeong (2014), "Food Waste Along the Food Chain", OECD Food, Agriculture and Fisheries Papers, No. 71, OECD Publishing, Paris. http://dx.doi.org/10.1787/5jxrcmftzj36-en

[24] J.C. Buzby, and J. Hyman, "Total and per capita value of food loss in the United States", Food Policy 37(2012): 561-570.

[25] J. Gustavsson , C. Cederberg , U. Sonesson And R. V. Otterdijk A. Meybeck. Global Food Losses And Food Waste. Food And Agriculture Organization Of The United Nations Rome, 2011. Isbn 978-92-5-107205-9. $28 \mathrm{P}$

[26] C. Sanders, A. Barber, G. Taylor.. Food Miles-Comparative Energy/Emissions Performance of New Zealand's Agriculture Industry. Research Report No. 285. Lincoln University, New Zealand. 105 p., 206

[27] C.J. Koroneos, Ch. Achillas, N. Moussiopoulos and E.A. Nanaki, "Life Cycle Thinking in the Use of Natural Resources". Open Environmental Sciences, 7, pp 1-6, 2013.

[28] J.F. Soussana. Research priorities for sustainable agri-food systems and life cycle Assessment. Journal of Cleaner Production 73: 19-23, 2014.

[29] W. Wakeland, Susan Cholette, and Kumar Venkat, "Food transportation issues and reducing carbon footprint" in J.I. Boye and Y. Arcand (eds.), Green Technologies in Food Production and Processing, 211 Food Engineering Series, DOI 10.1007/978-1-46141587-9 9, 2012

[30] UNEP. 2006. Background Report for UNEP Guide to Life Cycle Management. content/upload/2013/09/ UNEP_Background_document_LCM_2006_Febr.pdf

[31] E. Hertwich, "Life cycle approaches to sustainable consumption: a critical review". Environ Sci Technol 2005; 39 (13): 4673.

[32] European Commission. Towards a thematic strategy on the sustainable use of natural resources: communication from the commission to the council and the European parliament; Brussels: EC 2003

[33] I.Viola, A. Marinelli. "Sustainability of Well-Being International Forum". Food for Sustainability and not just food, FlorenceSWIF2015 Life Cycle Assessment and environmental sustainability in the food system. Agriculture and Agricultural Science Procedia 8 ( 2016 ) 317 - 323, 2015

[34] International Organization for Standardization, "Environmental management-Life cycle assessment-principles and framework," ISO 14040: 2006 (E), International Organization for Standardization, Geneva, Switzerland, 2006.
[35] K. R. Caffrey and M. W. Veal, 2013. "Conducting an Agricultural Life Cycle Assessment: Challenges and Perspectives". Scientific World Journal. Hindawi Publishing Corporation The Scientific World Journal Volume 2013, Article ID 472431, 13 pages, 2013. http://dx.doi.org/10.1155/2013/472431

[36] A. Bjørn, A. Laurent, M. Owsianiak and S. I. Olsen. "Goal Definition". (C) Springer International Publishing AG 2018 M.Z. Hauschild et al. (eds.), Life Cycle Assessment, DOI 10.1007/978-3319-56475-3_7] pp: 67-74, 2017.

[37] A. Bjørn, M. Owsianiak, A. Laurent, S. I. Olsen, A. Corona and M. Z. Hauschild.. Scope Definition. . (C) Springer International Publishing AG 2018 M.Z. Hauschild et al. (eds.), Life Cycle Assessment, DOI 10.1007/978-3-319-56475-3 7]. P75-116., 2017.

[38] A. Bjørn, A. Moltesen, A.Laurent, M. Owsianiak, A. Corona, M. Birkved and M. Z. Hauschild., "Life Cycle Inventory Analysis" M.Z. Hauschild et al. (eds.), Life Cycle Assessment pp 117-165, 2017. (C) Springer International Publishing.

[39] R.K. Rosenbaum, M.Z. Hauschild, A.M.-Marie Boulay, P. Fantke, A. Laurent, M.N. Núñez and M. Vieira. "Life Cycle Impact Assessment, Hauschild et al. (eds.), Life Cycle Assessment, pp 167-270, 2017.

[40] M.Z. Hauschild, "Introduction to LCA Methodology". () Springer International Publishing AG 2018 M.Z. Hauschild et al. (eds.), Life Cycle Assessment, DOI 10.1007/978-3-319-56475-3 7]. P59-66..

[41] J.I. Amate, M.G. de Molina. "Sustainable de-growth' in agriculture and food: an agro-ecological perspective on Spain's agri-food system (year 2000)". Journal of Cleaner Production 38 (2013) 27-35.

[42] C. Mena, and G. Stevens, ." Delivering performance in food supply chains: An introduction". In Delivering performance in food supply chains , 1st ed, ed. C. Mena and G. Stevens. London: Woodhead Publishing, 2010

[43] T. Nemecek, N. Jungbluth, L .M. Canals and R. Schenck. "Environmental impacts of food consumption and nutrition: where are we and what is next?". Int J Life Cycle Assess DOI 10.1007/s11367-016-1071-3. , 2016

[44] T. Nemecek, J. Schnetzer, J., Reinhard, J. (2014). "Updated and harmonised greenhouse gas emissions for crop inventories". Int $\mathbf{J}$ LCA 1-18. , 2014.

[45] Y. Arcand, D. Maxime, and R. Zareifard, "Life cycle assessment of processed food". in J.I. Boye and Y. Arcand (eds.), Green Technologies in Food Production and Processing, Food Engineering Series, DOI 10.1007/978-1-4614-1587-9_1, @ S Springer Science+Business Media, LLC , 2012.

[46] G. Haas, F. Wetterich and U. Geier. "Life cycle assessment framework in agriculture on the farm level"., International Journal of Life Cycle Assessment. 5, 6: 345_348, 2000.

[47] K. Hayashi, "Practical recommendations for supporting agricultural decisions through life cycle assessment based on two alternative views of crop production: the example of organic conversion," International Journal of Life Cycle Assessment, vol. 18, pp. 331-339, 2013

[48] I. J. M. Boer, "Environmental impact assessment of conventional and organic milk production," Livestock Production Science, vol. 80, no. 1-2, pp. 69-77, 2003.

[49] D. Tilman, M. Clark M, "Global diets link environmental sustainability and human health". Nature 515:518-522, 2014.

[50] L.M. Gruber, C.P. Brandstetter, U. Bos, J.P. Lindner, S. Albrecht, "LCA study of unconsumed food and the influence of consumer behavior". Int J Life Cycle Assess. (2016) 21:773-784, 2015.

[51] D. Saner, C. Beretta, B.Jäggi, R. Juraske, F. Stoessel, S. Hellweg, "Food Prints of households". Int J Life Cycle Assess. 21:654-663, 2015.

[52] U.G. Sonesson et al, "Paths to a sustainable food sector: integrated design and LCA of future food supply chains: the case of pork production in Sweden". Int J Life Cycle Assess. 21:664-676., 2015. 